\title{
HÆMODYNAMIC EFFECTS OF CHANGES IN BLOOD VOLUME IN HYPERTROPHIC OBSTRUCTIVE CARDIOMYOPATHY
}

\author{
BY \\ P. M. SHAH*, R. AMARASINGHAM, AND C. M. OAKLEY $\dagger$ \\ From the Department of Medicine (Clinical Cardiology), Postgraduate Medical School of London
}

Received September 23, 1964

Several physiological and pharmacological influences are known to alter the degree of obstruction in hypertrophic obstructive cardiomyopathy (hypertrophic subaortic stenosis, muscular subaortic stenosis). Increased left ventricular-arterial systolic gradients in the beats following a ventricular ectopic contraction and following the administration of isoprenaline and of digitalis are probably related to positive inotropic effects (Brockenbrough, Braunwald, and Morrow, 1961; Braunwald, Brockenbrough, and Frye, 1962; Braunwald and Ebert, 1962). The basic mechanism producing increased gradients during the Valsalva manœuvre, amyl nitrite inhalation, and nitroglycerine administration on the one hand, and diminished gradients with phenylephrine or methoxamine administration are not fully understood. The probable importance of changes in arterial pressure (Wigle et al., 1963) and of changes in ventricular volumes have been emphasized (Braunwald et al., 1964).

Cross and Salisbury (1963) succeeded in reproducing some of the hæmodynamic features of the disease in dogs by decreasing the cardiac output, provided the pericardium was closed. They first suggested that diminished ventricular volume was the factor responsible for subaortic obstruction. Should diminished cardiac output, blood volume, and ventricular size prove to be important determinants of increased obstruction in patients with hypertrophic obstructive cardiomyopathy then the therapeutic implications are obvious. Since treatment is not yet fully satisfactory or understood and the disease is most hazardous, it was decided to study the hæmodynamic effects of rapid withdrawal followed by reinfusion of blood.

These studies were carried out during diagnostic investigations to confirm the clinical diagnosis. The purpose of these studies was to determine the hæmodynamic parameters that affect adversely or beneficially the degree of obstruction in this disease. Knowledge of these is essential as a guide to therapy.

\section{SubJeCts AND Methods}

The present report concerns 6 patients: 2 women and 4 men whose ages varied from 26 to 50 years.

Simultaneous left ventricular (LV) and femoral artery (FA) pressures were recorded in all patients. The left ventricular pressures were measured following retrograde catheterization of the right femoral artery using the Seldinger technique in 5 (Professor R. E. Steiner or C.M.O.), and by transseptal catheterization in 1 patient. The left femoral artery was cannulated with a No. 2 Braun cannula or a No. 18 Cournand needle. In 5 patients, a cardiac catheter (No. 8 or 9 U.S.C.I.) was passed to the right atrium from an arm vein, and right atrial pressures were intermittently recorded.

* This work was supported by a Grant from the International Cardiology Foundation.

$\dagger$ In receipt of a Grant from the British Heart Foundation. 
Statham strain gauges (p23D) were used to register the pressures and the observations recorded on a N.E.P. multichannel photographic recorder. The cardiac outputs were measured by an indicator dye dilution technique using indocyanine green and the Gilford densitometer. The electrocardiogram was monitored continuously and a phonocardiogram was also recorded throughout the procedure.

Observations of simultaneous left ventricular, femoral artery, and right atrial pressures and cardiac output were made initially, after venesection of $500 \mathrm{ml}$., and then following rapid re-infusion of the blood. The left ventricular and femoral artery pressures were registered continuously during venesection and reinfusion procedures.

Venesection was accomplished by removal of $500 \mathrm{ml}$. of blood within 10 to 15 minutes through the catheter in the right atrium in 5 patients. In one other patient a forearm vein was used. The entire quantity was then re-infused into the patient via the route used for withdrawal. This was also completed within 10 to 15 minutes.

In 2 patients (No. 5 and 6) the entire procedures of venesection and re-infusion were repeated after $\beta$-adrenergic and parasympathetic blockade induced by the intravenous administration of $10 \mathrm{mg}$. I.C.I. 45520 (Inderal) and of $1 \mathrm{mg}$. atropine sulphate respectively.

TABLE

\begin{tabular}{|c|c|c|c|c|c|c|c|c|c|}
\hline $\begin{array}{l}\text { Patient } \\
\text { No. }\end{array}$ & Observation & $\begin{array}{l}\text { L.V. } \\
\text { syst. }\end{array}$ & $\begin{array}{l}\text { L.V. } \\
\text { E.D.P. }\end{array}$ & $\underset{(\mathrm{mm} . \mathrm{Hg})}{\text { F.A. }}$ & $\begin{array}{l}\text { L.V.-art. } \\
\text { systolic } \\
\text { gradient }\end{array}$ & $\begin{array}{c}\text { Heart } \\
\text { rate/min. }\end{array}$ & $\underset{\text { (1./min. })}{\text { C.O. }}$ & $\begin{array}{l}\text { S.V. } \\
\text { (ml.) }\end{array}$ & Comments \\
\hline 1 & $\begin{array}{l}\text { Initial } \\
\text { Venesection } \\
\text { Re-infusion }\end{array}$ & $\begin{array}{l}180 \\
125 \\
170 \\
140\end{array}$ & $\begin{array}{l}5 \\
0 \\
5 \\
5\end{array}$ & $\begin{array}{r}120 / 60 \\
85 / 50 \\
90 / 60 \\
100 / 60\end{array}$ & $\begin{array}{l}80 \\
40 \\
80 \\
40\end{array}$ & $\begin{array}{l}76 \\
84 \\
80\end{array}$ & $\begin{array}{l}4 \cdot 85 \\
5 \cdot 16 \\
6 \cdot 10\end{array}$ & $\begin{array}{l}60 \\
63 \\
76\end{array}$ & $\begin{array}{l}\text { Variations due } \\
\text { to arrhythmia } \\
\text { Sinus rhythm } \\
\text { re-established } \\
\text { Sinus rhythm }\end{array}$ \\
\hline 2 & $\begin{array}{l}\text { Initial } \\
\text { Venesection } \\
\text { Re-infusion }\end{array}$ & $\begin{array}{l}140 \\
120 \\
110\end{array}$ & $\begin{array}{r}10 \\
7 \\
15\end{array}$ & $\begin{array}{l}160 / 70 \\
125 / 60 \\
135 / 65\end{array}$ & $\begin{array}{r}-20 \\
-5 \\
-25\end{array}$ & $\begin{array}{l}60 \\
80 \\
60\end{array}$ & $\begin{array}{l}4 \cdot 35 \\
1 \cdot 50 \\
2 \cdot 76\end{array}$ & $\left.\begin{array}{l}72 \\
19 \\
47\end{array}\right\}$ & $\begin{array}{l}\text { Catheter } \\
\text { probably in } \\
\text { subvalvar } \\
\text { chamber }\end{array}$ \\
\hline 3 & $\begin{array}{l}\text { Initial } \\
\text { Venesection } \\
\text { Re-infusion }\end{array}$ & $\begin{array}{l}140 \\
190 \\
170 \\
118\end{array}$ & $\begin{array}{r}2 \\
10 \\
10 \\
5\end{array}$ & $\begin{array}{l}155 / 70 \\
135 / 85 \\
125 / 85 \\
140,90\end{array}$ & $\begin{array}{r}-15 \\
55 \\
45 \\
-22\end{array}$ & $\begin{array}{r}90 \\
100 \\
\frac{1}{100}\end{array}$ & $\begin{array}{l}5 \cdot 28 \\
3 \cdot 24 \\
\frac{7}{3 \cdot 72}\end{array}$ & $\left.\begin{array}{l}58 \\
\frac{32}{37}\end{array}\right\}$ & Pulsus alternans \\
\hline 4 & $\begin{array}{l}\text { Initial } \\
\text { Venesection } \\
\text { Re-infusion }\end{array}$ & $\begin{array}{l}160 \\
180 \\
125\end{array}$ & $\begin{array}{r}10 \\
0 \\
8\end{array}$ & $\begin{array}{l}135 / 70 \\
110 / 60 \\
140 / 70\end{array}$ & $\begin{array}{r}25 \\
70 \\
-15\end{array}$ & $\begin{array}{l}66 \\
74 \\
80\end{array}$ & $\begin{array}{l}8 \cdot 45 \\
6 \cdot 70 \\
8 \cdot 57\end{array}$ & $\begin{array}{r}128 \\
90 \\
107\end{array}$ & \\
\hline 5 & $\begin{array}{l}\text { Initial } \\
\text { Venesection I } \\
\text { Re-infusion I } \\
\text { i.v. ICI45520 } \\
\quad \text { +atropine } \\
\text { Venesection II } \\
\text { Re-infusion II }\end{array}$ & $\begin{array}{r}140 \\
135 \\
130 \\
125 \\
95 \\
125\end{array}$ & $\begin{array}{r}15 \\
5 \\
10 \\
10 \\
7 \\
17\end{array}$ & $\begin{array}{r}125 / 70 \\
115 / 65 \\
120 / 70 \\
120 / 75 \\
\\
80 / 52 \\
120 / 67\end{array}$ & $\begin{array}{r}15 \\
20 \\
10 \\
5 \\
15 \\
5\end{array}$ & $\begin{array}{l}76 \\
72 \\
75 \\
84 \\
77 \\
76\end{array}$ & $\begin{array}{l}6.05 \\
5.05 \\
5.55 \\
5.40 \\
\\
2.48 \\
4.60\end{array}$ & $\begin{array}{l}85 \\
70 \\
74 \\
64 \\
32 \\
62\end{array}$ & \\
\hline 6 & $\begin{array}{l}\text { Initial } \\
\text { Venesection I } \\
\text { Re-infusion } \\
\text { i.v. ICI45520 } \\
\quad \text { +atropine } \\
\text { Venesection II } \\
\text { Re-infusion II }\end{array}$ & $\begin{array}{l}170 \\
200 \\
175 \\
175 \\
160 \\
150\end{array}$ & $\begin{array}{r}20 \\
20 \\
15 \\
15 \\
7 \\
70\end{array}$ & $\begin{array}{r}105 / 60 \\
95 / 57 \\
100 / 65 \\
100 / 65 \\
75 / 50 \\
100 / 65\end{array}$ & $\begin{array}{r}65 \\
105 \\
75 \\
75 \\
85 \\
50\end{array}$ & $\begin{array}{l}72 \\
76 \\
75 \\
78 \\
72 \\
76\end{array}$ & $\begin{array}{l}6 \cdot 10 \\
4 \cdot 68 \\
5 \cdot 05 \\
4 \cdot 44 \\
3 \cdot 20 \\
3.92\end{array}$ & $\begin{array}{l}85 \\
61 \\
68 \\
57 \\
44 \\
55\end{array}$ & \\
\hline
\end{tabular}

i.v., intravenous; art., systemic artery; F.A., femoral artery; L.V., left ventricle; C.O., cardiac output; syst., systolic; E.D.P., end-diastolic pressure; S.V., stroke volume. 


\section{RESULTS}

The results are summarized in the Table.

Left Ventricular-arterial Systolic Gradients. Four patients having an initial gradient of 15 to $80 \mathrm{~mm}$. showed an increase following venesection (Fig. 1). In one other (No. 3) who had no initial gradient (femoral artery pressure higher than left ventricular systolic by $15 \mathrm{~mm}$.) a left ventricularfemoral artery systolic gradient of $55 \mathrm{~mm}$. was established after venesection. The remaining patient (No. 2) had no initial gradient (femoral artery systolic pressure exceeded left ventricular systolic pressure by $20 \mathrm{~mm}$.) and none developed after venesection (femoral artery systolic pressure was then $5 \mathrm{~mm}$. higher than the left ventricular pressure): in this patient it seemed likely that the tip of the left ventricular catheter had slipped out into the subvalvar chamber halfway through the study, as the hæmodynamic responses to ectopic beats and to amyl nitrite inhalation had also become negative, though they had been positive at the beginning of the study.

The arterial systolic pressures and pulse pressures fell after venesection in all patients. This fall was associated with a distinct rise of left ventricular systolic pressure in 3 patients. One (No. 1) initially had marked fluctuations in left ventricular systolic pressures and in gradients due to arrhythmia. After venesection sinus rhythm was established and the gradient stabilized near the maximum values observed initially. The left ventricular systolic pressure was unchanged in one patient (No. 5) and declined in the other (No. 2).

After re-infusion, the arterial systolic pressures and pulse pressures increased and the left ventricular systolic pressures were reduced in all patients, the left ventricular-arterial systolic gradients becoming significantly diminished (Fig. 1); the left ventricular end-diastolic and right atrial pressures were reduced after venesection and increased on re-infusion.

Figures 2 and 3 represent typical responses in 2 such patients (No. 3 and 4). Patient No. 3 showed ventricular alternans after venesection.

Cardiac Output. After venesection a fall in cardiac output of 15 to 60 per cent was noted in 5 patients. In 3 of these, re-infusion was
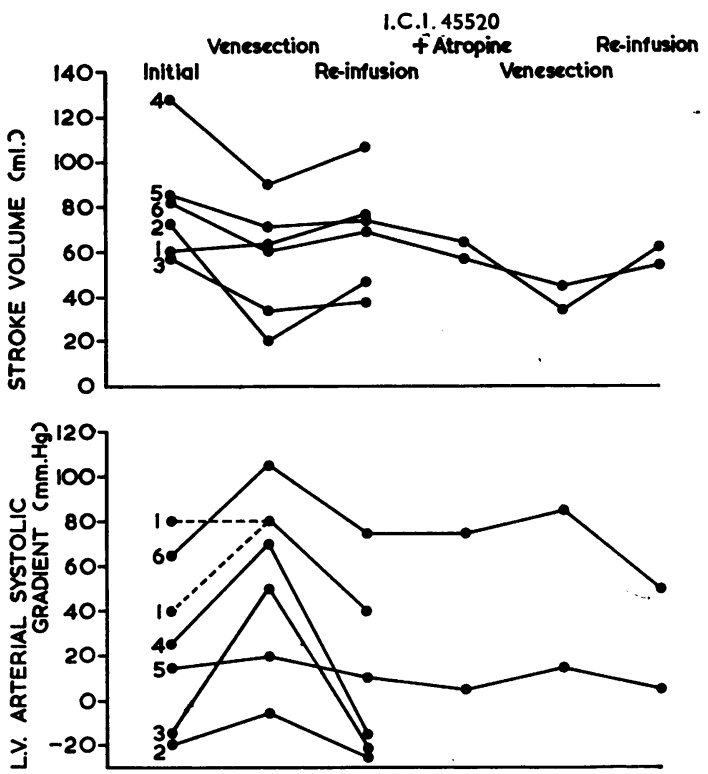

Fig. 1.-Variations in stroke volumes and in left ventricular-arterial systolic gradients in 6 patients with hypertrophic obstructive cardiomyopathy after venesection and re-infusion procedures. These were repeated in two after $\beta$-adrenergic blockade (I.C.I. 45520 Inderal) and parasympathatic blockade (atropinz).

followed by a return to, or near to, the initial

level, while in the other 2 , though some increase in cardiac output was noted, the initial levels were not reached. In one other (No. 1) the output was not significantly altered after venesection and showed some increase after re-infusion.

The cardiac rate was not appreciably altered by either the venesection or the re-infusion procedures. The calculated stroke volume, therefore, was reduced after venesection and increased after re-infusion in 5 patients. In patient No. 1, whose output was unchanged after venesection, the stroke volume was also essentially unaltered.

Thus venesection resulted in a fall in cardiac output and stroke volumes; however, left ventricularfemoral arterial systolic gradients increased in 5 of the 6 patients. These effects were reversed after re-infusion (Fig. 1). 


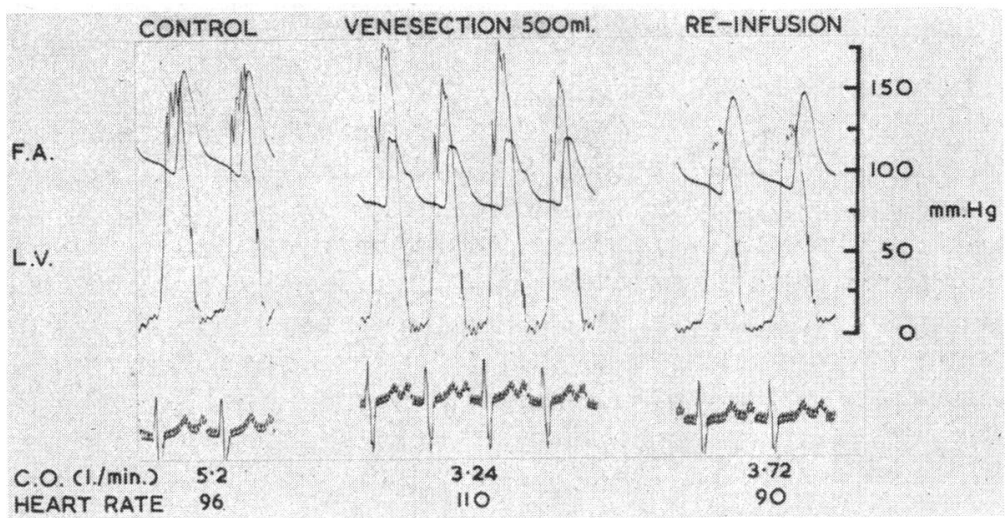

Fig. 2.-Result of rapid withdrawal and re-infusion of blood with patient No. 3. Note the higher L.V. pressure with ventricular alternans after venesection.

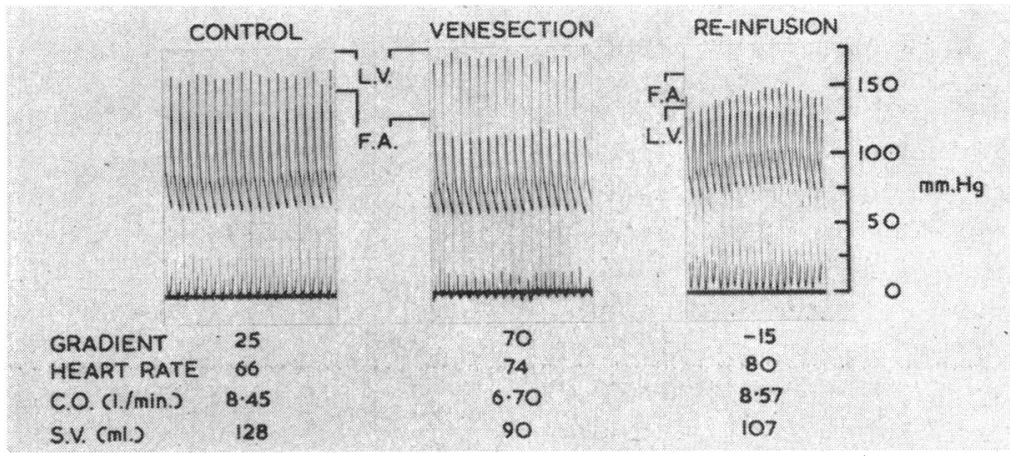

Fig. 3.-A typical response of rapid withdrawal and re-infusion of blood in one patient (No. 4) on left ventricular (L.V.) and femoral artery pressures, heart rate, cardiac output (C.O.), and stroke volumes (S.V.).

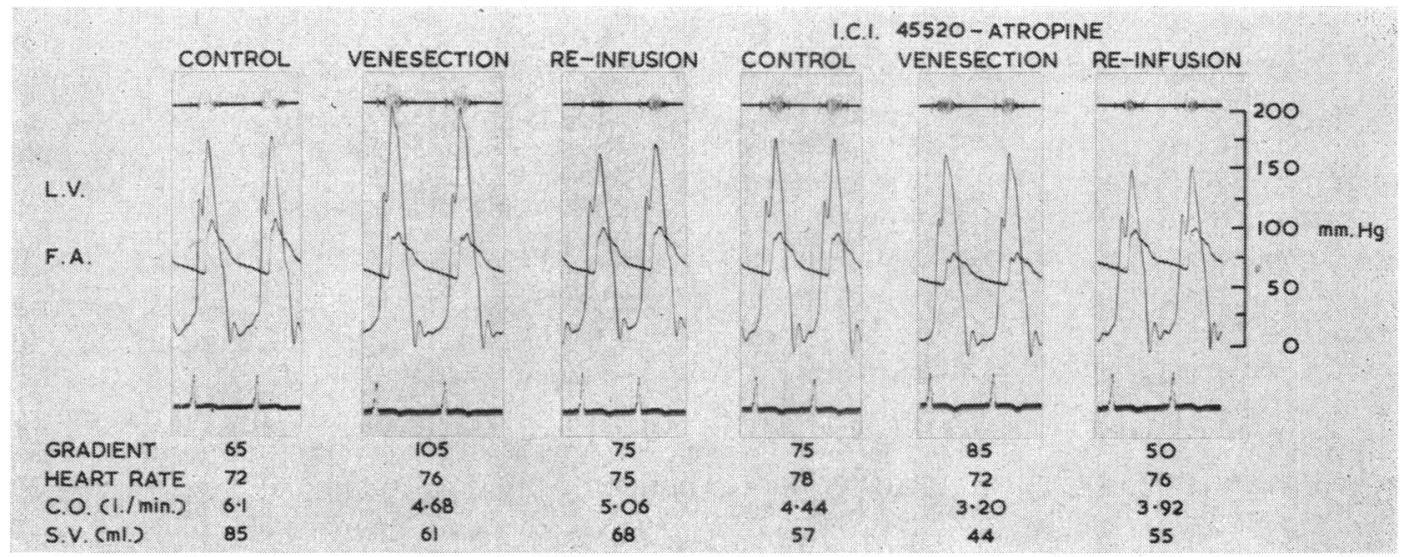

FIG. 4.-Results of withdrawal and re-infusion of blood on systolic gradients. Heart rate, cardiac output (C.O.), and stroke volumes (S.V.) before and after adrenergic (I.C.I. 45520) and parasympathetic blockade (atropine) in one patient (No. 6). 
$\beta$-adrenergic and Parasympathetic Blockade. In 2 patients (No. 5 and 6), in whom the study was repeated after $\beta$-adrenergic blockade with intravenous I.C.I. 45520 (Inderal) and parasympathetic blockade with intravenous atropine sulphate, no significant difference in the left ventricular and femoral artery pressure changes was observed after inducing the autonomic blockade compared with before it. However, the cardiac output and heart rate were slightly altered resulting in a decrease of stroke volume. The venesection was followed by a more marked fall in cardiac output in both the subjects, being of the order of 48 and 27 per cent as against 15 and 20 per cent initially. This resulted in considerable reduction in stroke volumes (Fig. 1). The left ventricular-femoral artery systolic gradients increased, as a result of a greater fall in femoral artery than in left ventricular systolic pressure. Re-infusion was followed by an increase in cardiac output, stroke volume, and left ventricular and arterial systolic pressures, but a decrease in left ventricular-femoral artery systolic gradients.

Figure 4 illustrates the course of events in patient No. 6.

\section{DisCUSSION}

A significant increase of left ventricular-arterial systolic gradients in 5 out of 6 patients with hypertrophic obstructive cardiomyopathy in the face of a diminished cardiac output and stroke volume after venesection indicated an important increase in outflow obstruction. Opposite changes after re-infusion were the result of diminished obstruction. These effects of venesection and reinfusion were not altered by either $\beta$-adrenergic or vagal blockade in either of the patients in whom this was studied, presumably indicating that the responses were not reflexly mediated. Since the heart rate was essentially unaltered during the various studies with patients in the supine position, the variable obstruction appears to have been causally related to the variations in blood volume. Thus, after venesection the cardiac output and blood volume were reduced, the left ventricular enddiastolic pressure was lower, and the size of the left ventricular cavity was probably diminished, thus favouring increased obstruction to left ventricular outflow. On re-infusion, increase in the size of the left ventricular cavity which was filled at a higher left ventricular end-diastolic pressure presumably prevented the approximation of hypertrophied muscle in the outflow tract, and thus the obstruction was lessened.

A rather alarming reduction in cardiac output after the second venesection procedure following $\beta$-adrenergic block and vagal block was noted in both the patients so studied. Since the heart rate was not significantly altered the fall may have been due to changes in the peripheral vascular bed. It has been suggested from well-controlled observations that the systemic venous bed contains both $\alpha$ - and $\beta$-adrenergic receptors and stimulation of either results in veno-constriction (Kaiser, Ross, and Braunwald, 1964). It is conceivable that $\beta$-adrenergic blockade induced by I.C.I. 45520 prevented the veno-constriction that was necessary to maintain cardiac output after venesection. These effects following $\beta$-adrenergic blockade thus need to be carefully examined.

The results of the present study offer a probable explanation for the mechanism of variations in the left ventricular outflow obstruction in this disease under various influences. Increased obstruction during peak strain of the Valsalva manœuvre, and during expiration (with slow deep breathing), is probably related to decreased inflow into the left ventricle and decreased ventricular volume (Shah et al., 1964). Venesection intensified and re-infusion reduced or abolished these respiratory variations. Similarly amyl nitrite inhalation and nitroglycerine presumably act in this way (Wigle et al., 1963; Goodwin et al., 1964). Reduced systolic volume from increased vigour of contraction during inotropic stimulation would bring into line the increased obstruction resulting from drugs such as isoprenaline. Conversely, administration of vaso-active drugs such as phenylephrine or methoxamine with attendant bradycardia probably results in increased ventricular volume which in turn would diminish obstruction. The increase in the left ventricular end-diastolic pressure with phenylephrine despite a decreased gradient tends to support this suggestion (Goodwin et al., 1964).

Braunwald et al. (1964) have suggested that a reduced systolic size of the left ventricle is the unifying factor among the various influences that increase obstruction in hypertrophic obstructive cardio- 
myopathy. It is possible that the cavity size in mid-systole (at the time when the obstruction becomes hæmodynamically apparent) is the major determining factor. Thus, influences such as the Valsalva manœuvre or venesection result in a reduction in diastolic size of the left ventricle. A relatively normal early ejection would further reduce the size of the cavity until a critical point is reached when the obstruction can be hæmodynamically apparent. Furthermore, positive inotropic influences such as the administration of digitalis or isoprenaline which are shown to increase obstruction may act by producing an increased ejection of blood in early systole, which results in a critical reduction in the size of the left ventricular cavity. The post-ectopic beat following a long diastolic pause is shown to be associated with increased obstruction in this condition. The explanation for this is not apparent since the end-diastolic pressure and probably the end-diastolic volume are increased after a long diastolic pause. This pause is followed by a stronger beat which may also be more effective in increasing the amount of blood ejected during systole. On the other hand, it is quite probable that positive inotropic influences act independently of ventricular size and favour obstruction in spite of increased dimensions. It may be pointed out that the results of the present study do not refute the alternative hypotheses that variations in aortic and arterial pressures are the determinants of variable obstruction in this disorder. This view was originally put forward by Brock (1957) and has been recently championed by Wigle et al. (1963). In the present study venesection was uniformly associated with reduced arterial pressures while re-infusion was associated with increased pressures. It is our opinion that a greater reduction in arterial systolic as compared to left ventricular pressure is the result rather than the cause of increased obstruction.

The present work confirms the experimental observations of Cross and Salisbury (1963). These authors produced hæmodynamic evidence of left ventricular outflow obstruction in 10 out of 23 normal dogs by a deliberate reduction in cardiac output, with the pericardium intact. In 13 other dogs, additional inotropic intervention produced a functional obstruction. They observed that a critical reduction of minute volume (usually $50 \mathrm{ml} . / \mathrm{kg} . / \mathrm{min}$.) was required to induce obstruction. These effects were prevented by opening the pericardium. Since the functional obstruction could be influenced by positive inotropic influences such as isoprenaline and also by negative inotropic influences such as hypothermia they did not consider either the heart rate or the ejection velocity to be the basic mechanism.

It is possible that a critical reduction in the size of the left ventricular cavity is essential for obstruction to become manifest in hypertrophic cardiomyopathy, and that this may vary from one patient to another depending on the degree and situation of the hypertrophied muscle in relation to the outflow tract. Judging from our present results and the experimental observations by Cross and Salisbury (1963) on the effect of ventricular size on obstruction, we have speculated that the beneficial effects of various operations undertaken for this condition are related merely to pericardiotomy which permits the ventricular volume to increase (Bentall et al., 1964). Increase in blood volume in left ventricular failure has been attributed to aldosterone release reflexly mediated through a rise in left atrial pressure. In the absence of heart failure such a sequence may even explain the high output and absence of outflow obstruction seen in some patients with non-obstructive hypertrophic cardiomyopathy and explain also occasional spontaneous progression from a seriously obstructed into a non-obstructed phase of the disease (unpublished observations).

The therapeutic implications of our observations that venesection increases the functional obstruction in this disease while infusion ameliorates obstruction are apparent. Caution seems to be warranted in the use of diuretics in this condition for enthusiastic treatment with diuretics may significantly reduce blood volume and paradoxically worsen obstruction. Since digitalis and isoprenaline are shown to increase obstruction their use is generally contraindicated in this disease. Similarly, nitroglycerine for relief of angina in these patients may prove to be harmful. One young patient in our series who had been prescribed nitroglycerine noticed considerable subjective distress and preferred to bear the anginal pain to the distress caused by its attempted treatment.

Judging from the results of the present study on the effects of blood volume, it is possible that expansion of circulating blood volume (achieved perhaps by administration of albumin) may offer 
a therapeutic approach. In this respect the hæmodynamic effects of increased blood volume during pregnancy may prove to be beneficial. However, the adverse effects of increased levels of circulating catecholamines cannot be ignored and the final outcome of an altered physiological state remains unpredictable. Since the adverse hæmodynamic effects of catecholamines are well established, studies to determine the long-term effects of treatment with $\beta$-adrenergic blocking drugs such as pronethalol or I.C.I. 45520 (Inderal) are in progress. We are also attempting to study the effect of drugs such as reserpine which deplete the tissue stores of catecholamines.

\section{SUMMARY}

During the course of diagnostic investigations, the effects of rapid changes in blood volume on left ventricular outflow obstruction were examined in 6 patients with hypertrophic obstructive cardiomyopathy. Venesection resulted in a diminished cardiac output and stroke volume, while the left ventricular-arterial systolic gradients increased. The obstruction was relieved following a rapid re-infusion of blood and the cardiac outputs and stroke volumes were restored. These effects of changes in blood volume persisted after $\beta$-adrenergic and parasympathetic blockade in 2 patients so studied.

Increased obstruction with decreasing blood volume is probably related to decreased dimension of the left ventricular cavity. On the basis of our results, the mechanism of the hæmodynamic effects of various manœuvres and drugs that influence obstruction in this disease are discussed. Various therapeutic approaches that may prove harmful are indicated, and the possible modes of treatment that may be beneficial are discussed.

We wish to thank Professor J. F. Goodwin and Professor R. E. Steiner for valuable guidance and help during the course of these studies. We are also thankful to Mr. Gerald Rainbow and Mrs. Phyllis Smy for excellent technical assistance and to Mrs. Angela Cartwright for efficient secretarial help. We would also like to thank the Department of Medical Illustration.

\section{REFERENCES}

Bentall, H. H., Cleland, W. P., Oakley, C. M., Shah, P. M., Steiner, R. E., and Goodwin, J. F. (1964). The surgical treatment and post-operative hæmodynamic studies of hypartrophic obstructive cardiomyopathy. Brit. Heart $J$. In the press.

Braunwald, E., Brockenbrough, E. C., and Frye, R. L. (1962). Studies on digitalis. V. Comparison of the effects of ouabain on left ventricular dynamics in valvular aortic stenosis and hypertrophic subaortic stenosis. Circulation, 26, 166.

- and Ebert, P. A. (1962). Hemodynamic alterations in idiopathic hypertrophic subaortic stenosis induced by sympathomimetic drugs. Amer. J. Cardiol., 10, 489.

response of patients with idiopathic hypertrophic subaortic stenosis to nitroglycerin and to Valsalva maneuver. Circulation, 29, 422.

Brock, R. (1957). Functional obstruction of the left ventricle (Acquired aortic subvalvar stenosis). Guy's Hosp. Rep., 106, 221.

Brockenbrough, E. C., Braunwald, E., and Morrow, A. G. (1961). A hemodynamic technic for the detection of hypertrophic subaortic stenosis. Circulation, 23, 189.

Cross, C. E., and Salisbury, P. F. (1963). Functional subaortic stenosis produced in animals. Amer. J. Cardiol., $12,394$.

Goodwin, J. F., Shah, P. M., Oakley, C. M., Cohen, J., Yipintsoi, T., and Pocock, W. (1964). In Ciba Symposium on Cardiomyopathies, ed. G. E. Wolstenholme and M. O'Connor. London, Churchill.

Kaiser, G. A., Ross, J., Jr., and Braunwald, E. (1964). Alpha and Beta adrenergic receptor mechanisms in the systemic venous bed. J. Pharmacol. exp. Ther., 144, 156.

Shah, P. M., Yipintsoi, T., Amarasingham, R., and Oakley, C. (1964). Effects of respiration on hæmodynamics of hypertrophic obstructive cardiomyopathy. Amer.J. Cardiol. In the press.

Wigle, E. D., Lenkei, S. C. M., Chrysohou, A., and Wilson, D. R. (1963). Muscular subaortic stenosis: The effect of peripheral vasodilatation. Canad. med. Ass. J., 89, 896. 